\title{
PARADIPLOMACIA E PODER LEGISLATIVO NO RIO GRANDE DO SUL: UM RELATO SOBRE A COMISSÃO MISTA PERMANENTE DO MERCOSUL E ASSUNTOS INTERNACIONAIS (1996-2002) ${ }^{1}$
}

\author{
Marcos Pascotto Palermo²
}

Resumo

Este artigo analisa as atividades da Comissão Permanente do Mercosul e Assuntos Internacionais na Assembleia Legislativa do Estado do Rio Grande do Sul no período de 1996 a 2002. O objetivo deste estudo é diagnosticar quais são os ganhos políticos na atuação do parlamentar desta Comissão e até que ponto realmente está sendo discutida a integração latino-americana em suas tarefas. Atenta para

10 presente trabalho é um resumo de aspectos abordados no trabalho monográfico de conclusão de curso intitulado "A Comissão do Mercosul na Assembléia Legislativa do Estado do Rio Grande do Sul (1996-2002)", apresentado pelo autor como requisito parcial para a obtenção do grau de Bacharel em Ciências Sociais na Universidade Federal de Santa Maria (UFSM). Nesta versão, tenta-se estabelecer diálogo com a questão da paradiplomacia, dada a pertinência do relato estudado. 0s limites possíveis de serem encontrados neste artigo são 0 da adaptação do estudo de caso ao espaço permitido para a apresentação na forma de papere às exigências da temática do evento em que foi apresentado, o III Fórum Regional de Relações Internacionais "A Emergência da Paradiplomacia na Política Internacional". A monografia original faz parte do acervo da Biblioteca Central da UFSM.

2 Professor Auxiliar do Centro Universitário Franciscano (UNIFRA). Especialista em Direito Internacional Público e Privado e Direito da Integração pela Universidade Federal do Rio Grande do Sul (UFRGS). Mestrando em Ciências Sociais pela UFSM e em Direito pela UFRGS. 
a alteração da forma e conteúdo das mesmas, dando importância às atividades que podem ser consideradas ligadas à paradiplomacia nesse Estado.

Palavras-chave: Poder Legislativo. Mercosul. Paradiplomacia.

\section{Abstract}

This paper analyses the activities of the Mercosur Permanent Commission and International Affairs of the Legislative Assembly of the State of Rio Grande do Sul from 1996 to 2002. This study aims to diagnose the political advantages on the parliamentarian's performance of this Commission and the extent that is being discussed Latin - American integration in its tasks. Furthermore, it focuses on the alteration of the form and content of these assignments, taking in account activities which can be considerate linked to paradiplomacy in this State.

Key words: Legislative Power. Mercosul. Paradiplomacy.

\section{INTRODUÇÃO}

A proposta de integração latino-americana trazida pelo Tratado de Assunção, em 1991, estabelece um modelo integrativo regional, de caráter intergovernamental, o Mercosul, composto, então, por Brasil, Argentina, Uruguai e Paraguai. A criação do bloco trouxe a possibilidade de se trabalhar com o tema mercosulino na Assembleia 
Legislativa do Rio Grande do Sul. Em 1995, ocorre a criação de uma comissão parlamentar especial e temporária, que deu origem a uma comissão permanente, em 1996. O incentivo para a existência desse projeto foi dado pela Constituição Federal de 1988, na qual se vê que a questão da integração latino-americana é recepcionada em seu art. $4^{\circ}$, onde se trata dos princípios que regem as relações internacionais do Brasil. No parágrafo único desse artigo diz-se que a República Federativa do Brasil tem por escopo buscar a integração econômica, política social e cultural dos povos da América Latina, visando à formação de uma comunidade latino-americana de nações.

Tal previsão constitucional fornece arcabouço institucional para que se possa pensar na formação de iniciativas legislativas para se concretizar essa integração. Não se olvida, contudo, que existem limitações institucionais dadas ao poder de legislar sobre temas pertinentes à política externa, mesmo de integração regional, no âmbito das unidades federadas brasileiras, como os estados e os municípios. $\mathrm{Na}$ opinião de Seitenfus (2004), os Estados federais encontram-se no dilema de conceder atribuições indispensáveis na esfera internacional às suas unidades autônomas, correndo o risco de dispersão, contradições e enfraquecimento.

A atuação destas unidades, na dita ordem internacional globalizada visando à consecução de seus interesses, recebe, em sentido lato, o nome de paradiplomacia. Este fato tem sido o alvo de pesquisas dos estudiosos das Relações Internacionais contemporâneas. Concorda-se com o autor citado, quanto ao fato de que não há uma teoria solidificada quanto ao tema.

Mesmo sabendo que os parlamentares gaúchos estão sujeitos 
a uma barreira constitucional quanto a atividades relativas às relações internacionais, viu-se a criação de um espaço de discussão destes assuntos exteriores. Estes, também passam pelo filtro daquilo que pode se considerar como funções de uma legislatura. La Palombara (1982), ao estudar estas funções, classificava-as em cinco: I- Elaboração de regras; II - Representação; III - Articulação e Agregação de Interesses; IV- Socialização e educação política, V- Supervisão, Observação e Fiscalização. Vê-se que uma comissão, por ser o microcosmo do plenário, tende a expressar as características da atuação de uma legislatura sobre determinado tema. Ainda, a perspectiva dos modelos do novo institucionalismo acerca da atuação dos parlamentares, trazidos por Limogi (1994), é pertinente para explicar posturas políticas guiadas por um viés de racionalidade ${ }^{3}$.

O objetivo deste artigo é o de diagnosticar quais são os ganhos políticos na atuação do parlamentar nesta Comissão e até que ponto, realmente, se discute integração internacional nos seus trabalhos. Atentar-se-á para a alteração da forma e conteúdo dos afazeres em duas legislaturas: a 49a Legislatura, que acompanhou o Governo de Antonio Britto (1994-1998) e a 50a Legislatura, correspondente ao governo de Olívio Dutra (1998-2002)4. Da mesma forma, pensa-

3 Tanto as funções de uma legislatura aqui citadas, quanto os modelos neoinstitucionalistas existentes (distributivista, informacional e partidário), demandariam um estudo que foge ao escopo e espaço deste trabalho. Recomenda-se, todavia, a leitura das obras dos autores citados nas referências existentes.

40 recorte temporal deu-se em virtude de que, à época de feitura do trabalho original (2005), haviam transcorrido por completo apenas duas legislaturas desde a criação da referida Comissão. 
InterAção | 237

-se que a atuação em questão reflete um modo de se aplicar a paradiplomacia, realizada, neste caso, não pelos Poderes Executivos locais, mas por um órgão legislativo.

\section{0 desenvolvimento das atividades: a representação das bases eleitorais, interiorização das reuniões e a posterior polarização entre governo e oposição}

Os políticos que se elegem para o Poder Legislativo possuem os seus redutos eleitorais e tendem a ser identificados por outros deputados como representantes dos mesmos, quando não se identificam a si próprios com os referidos redutos. Pode-se ver, ao analisar as reuniões transcritas, que a posição das bases eleitorais é bastante salientada. Como outro exemplo, há a transcrição que segue, oriunda da participação do então presidente da Comissão, Deputado Marco Peixoto:

O Município de Itaqui nos enviou convite, solicitando um importante encontro, uma vez que é cidade fronteiriça e que tem problemas em sua fronteira com a Argentina. O Deputado Caio Repiso Riela poderá nos auxiliar no agendamento deste encontro. O Município de Imbé, que pertence à região de onde é oriundo o Deputado Ciro Simoni, já marcou uma reunião na qual o referido parlamentar representará esta comissão. O Município de Pelotas, cujo representante é o Deputado Bernardo de Souza, Presidente da Comissão de Constituição de Justiça, abriu uma oportunidade ímpar - já que esta Assembleia Legislativa deveria realizar a sua segunda reunião do processo de descentralização naquele município - para que a Comissão do Mercosul promova, lá, um encontro 
238 | InterAção

importante com a presença, inclusive, das universidades daquele município. ${ }^{5}$

A isto se associa, ainda que no universo simbólico, uma dose de ufanismo pelo lugar de origem em determinados casos. Os parlamentares reivindicam a proximidade sua ou de outro deputado como próxima de sua base eleitoral. Estas expressões foram constatadas ao se analisar as transcrições e atas das reuniões realizadas pela Comissão. Dentro deste universo simbólico, o deputado ou auxiliar da comissão tende a ser parte legítima da comunidade que diz representar, no caso a sua "paróquia" eleitoral. Vê-se a manifestação do deputado Caio Repiso Riela, em 15 de maio de 1996:

Temos assessoria qualificada para agendar essas reuniões, na pessoa do ex-deputado Júlio Cezar Caspani, uruguaianense, nosso conterrâneo, que emprestamos a Cachoeira do Sul, cuja presença e atuação nesta comissão muito nos orgulha. ${ }^{6}$

Esta citação do assessor ou membro parlamentar como conterrâneo, companheiro da cidade que se defende, aparece, por exemplo, no discurso do Deputado Bernardo de Souza na reunião de 21 de agosto de 1997, durante a entrega de reivindicações de entidades da Zona Sul do estado, à Comissão7:

5 Extraído de sua participação na reunião do dia 15 de maio de 1996, cuja transcrição da reunião gravada se encontra disponível on line no site da Assembleia Legislativa do Rio Grande do Sul: http://www.alrs.gov.br/anais. Acesso em 10 de setembro de 2004. 6 Cuja transcrição da reunião gravada se encontra disponível on line no site da Assembleia Legislativa do Rio Grande do Sul: http://www.alrs.gov.br/anais. Acesso em 10 de setembro de 2004.

7 Cuja transcrição da reunião gravada se encontra disponível on line no site da Assembleia Legislativa do Rio Grande do Sul: http://www.alrs.gov.br/anais. Acesso em 11 de setembro de 2004. 
InterAção | 239

O Deputado Marco Peixoto tem uma disposição para que esta comissão seja uma efetiva agente na elaboração de estratégias para as questões da integração - atitude ímpar no Brasil, em nível de Assembleia Legislativa. Trata-se de um homem que possui uma relação afetiva e que faz questão de registrar - e por isso vou torná-la pública -, com Pelotas. Da mesma forma que o Deputado Quintiliano Vieira, S.Exa. também frequentou os bancos acadêmicos desta cidade. S. Exa. é um pouco pelotense e por isso tem dado atenção à nossa terra.

A questão da representação se estabelece como semelhança nas duas legislaturas estudadas. Salienta-se a saudação de abertura da 50a Legislatura feita pelo então presidente Marco Peixoto, ao se referir ao deputado Luis Augusto Lara:

Saudamos os colegas deputados, em particular o vice-presidente desta comissão, Luis Augusto Lara, jovem deputado chegando para seu primeiro mandato, a quem desejamos uma gestão profícua, em que possa desenvolver o seu trabalho, especialmente na sua região, a de Bagé. ${ }^{8}$

Ver-se-á em seguida que, do ponto de vista prático, esta representação simbólica ao lugar de origem esconde a necessidade de se preservar e dar uma satisfação ao ponto de maior expressão eleitoral de determinados políticos. Toma-se o deputado como um ser racional que visa a sua reeleição e traça a melhor estratégia para tanto. No caso

8 Extraído da participação do deputado Marco Peixoto na reunião do dia 24 de março de 1999, cuja transcrição da reunião gravada se encontra disponível on line, no site da Assembleia Legislativa do Rio Grande do Sul: http://www.alrs.gov.br/anais. Acesso em 12 de setembro de 2004. 
da bibliografia estudada por Limongi (1994), vê-se formalmente uma instituição erigida, o voto distrital, que obrigaria um deputado racionalmente comprometido com sua reeleição a trabalhar em prol de seu distrito. Não existe tal instituição no caso brasileiro.

Contudo, se analisarmos a característica da votação dos deputados envolvidos, tem-se muitas vezes que suas bases eleitorais representam percentualmente mais da metade das votações dos mesmos. Isto se dá principalmente com os deputados mais diretamente envolvidos nos trabalhos efetivos da Comissão. Chega-se próximo de um desempenho eleitoral de quase cem por cento. Com isto, se verifica que apesar de o Brasil usar o voto proporcional, as bases eleitorais funcionariam como uma espécie de distrito simbólico. Isto será demonstrado na análise quantitativa exposta adiante.

Os então deputados, Caio Riela e Quintiliano Vieira, por exemplo, com relação à Zona do Pampa ${ }^{9}$ e Bernardo de Souza, na região de Pelotas, são casos de votação concentrada na primeira legislatura estudada, assim como Frederico Antunes e Luis Augusto Lara, na segunda legislatura. Tendo-se como exemplo dois deputados de cada legislatura, vê-se que mesmo o voto proporcional tomado por instituição, não desobriga um deputado a trabalhar por seu reduto, como se este fosse quase um distrito, dada a deferência e a magni-

9 Tomamos como Zona do Pampa, uma região que por critérios geográficos do estado do Rio Grande do Sul engloba a Fronteira Oeste, cujos principais municípios são os de Uruguaiana, Alegrete, Quaraí, Barra do Quaraí, Maçambará, Manoel Viana, Rosário do Sul, Santana do Livramento, São Gabriel e São Borja e a chamada região da Campanha, cujos principais municípios são Bagé, Caçapava do Sul, Candiota, Dom Pedrito, Lavras do Sul e Hulha Negra. 
InterAção | 241

tude da votação que nestes municípios recebem. Isto também tende a explicar a representação que emerge num universo, o simbólico do reduto eleitoral, do qual o deputado representa.

Outro aspecto é o da interiorização das atividades da Comissão. Considerando-se a perspectiva do modelo distributivista, também deve ser analisada a divisão dos recursos pelos redutos eleitorais dos deputados. Uma vez realizada reunião ou projeto em determinada localidade ou região, os recursos alocados tendem a ter seus custos distribuídos pelo todo, como já foi explanado na revisão da literatura sobre o tema. Enquanto os ganhos políticos se dão em específico para o deputado que os alocou, e que, com certeza, será a localidade cuja votação é mais expressiva. Esta questão deve ser analisada com cuidado, pois a Comissão do Mercosul não tratou, em suas reuniões, de destino de repasse de verbas para determinadas regiões, por exemplo. Contudo, a prática da interiorização das reuniões tende, por óbvio, a acarretar gastos e a se tornar importante quando há interesse de se expressar as reivindicações e resoluções de problemas de determinadas regiões. $\mathrm{O}$ mesmo ocorre quando se faz um projeto com a aprovação da comissão. Há uma tendência de se tentar deslocar os trabalhos e a atenção da Comissão para estes redutos de origem, que é de certa forma alimentada pela perspectiva de interiorização, dada pela direção da mesma num primeiro período.

As questões fronteiriças, por exemplo, abrem a possibilidade de se realizar esta interiorização de forma a se dar atenção às cidades com condição de fronteira. Vê-se a questão da mediação entre a comunidade destas regiões e o Ministério das Relações Exteriores, bem como com a Comissão Parlamentar do Mercosul na Câmara Federal. 
Esta mediação se torna atividade realizada pelos deputados em virtude da própria limitação institucional existente quanto a legislar sobre os assuntos do Mercosul e de manter capacidade de negociar a integração de forma mais direta. Um exemplo disso é dado por questões como o caso de problema de aduanas, relativos às exportações e ao de roubo de cargas.

Como procedimento de trabalho da Comissão, esta perspectiva de interiorização foi incluída no início das suas atividades, em maio de 1996. A incidência dessa atividade já nos primeiros meses de atividade foi bastante grande. Em 07 de agosto de 1996, o deputado Marco Peixoto salientava que esse era o segundo objetivo da Comissão, após a divulgação do que seria Mercosul:

Em segundo lugar, decidimos ir ao interior do Estado e ouvir aqueles que praticam o Mercosul no dia-a-dia, especialmente na Região da Fronteira Oeste. Já estivemos em São Borja, Santiago, Uruguaiana, Itaqui, Porto Mauá. Ainda iremos a Pelotas e a outras cidades.

No entanto, há uma diminuição deste procedimento nos anos seguintes, sem, contudo, deixar de ser adotado em quase todos os anos estudados; especialmente, em anos que não antecediam às eleições.

As regiões da Fronteira Oeste e Campanha, Região Sul e Litoral (Norte e Sul) foram as mais citadas nos trabalhos, bem como houve, ao longo do tempo, uma boa visitação por parte da Comissão em seus municípios. Daí se extrai a análise que segue de cada uma das regiões mais representadas.

As próprias comunidades se organizavam como diretamente interessadas em fazer da Comissão um palco para as suas reivindica- 
InterAção | 243

ções, enquanto cidades fronteiriças e com as peculiaridades que thes são características, tais como a questão de comércio entre as cidades brasileiras e estrangeiras, e a questão do tráfego para cidades de divisa, bem como relativas ao turismo, para as de litoral. As reuniões da comissão se tornam alvo de visita das entidades municipais. Um exemplo disso é a presença de membros das Câmaras Municipais nas mesmas. É o caso de São Borja, por ocasião da primeira reunião, que já se fazia representar salientando sua posição de cidade de fronteira e como parte da Metade Sul do estado ${ }^{10}$.

Quanto às reuniões estudadas, vê-se que a região da Zona do Pampa, ${ }^{11}$ que engloba a Região da Campanha e Fronteira Oeste do estado do Rio Grande do Sul, aparece bastante representada. Transcrevendo-se os discursos dos deputados veem-se estas expressões. No discurso do deputado Caio Repiso Riela, de 15 de maio de 1996, tem-se a seguinte colocação:

Gostaríamos que a Comissão do Mercosul promovesse - afora essas reuniões que estão sendo

10 Atente-se para a participação do vereador João Manoel Bicca, de São Borja, 15 de maio de 1996: "Nós, da fronteira, também pertencemos à metade sul e queremos participar das benesses capitaneadas pelo presidente FHC". Informação disponível no site da Assembléia Legislativa do Rio Grande do Sul: http://www.alrs.gov.br/anais. Acesso em 10 de setembro de 2004.

11 Não é levada em consideração, nos discursos dos deputados estaduais, a subdivisão geográfica, o que coloca Região da Campanha mesclada à Fronteira Oeste, e muitas vezes vinculando o deputado à mesma região. Isto levou à opção de englobar as subdivisões num mesmo espaço na análise destas reuniões. 0corre, também, que a votação dos deputados desta região é expressiva nas duas divisões, como é o caso de Quintiliano Vieira, que contou com as maiores votações em Dom Pedrito (Região da Campanha) e Santana do Livramento (Fronteira Oeste). Informação disponível em: www.nupegs.ufrgs.ifch.br. Acesso em 03 de setembro de 2005. 
244 | InterAção

solicitadas e que o membro titular pode representá-la como disse o presidente com todos os poderes - a interiorização dos trabalhos desta comissão, isto é, em vez de realizarmos as reuniões às quartas-feiras, às 11 horas, poderíamos realizá-las nas segundas ou nas sextas-feiras nas cidades da fronteiras e também em outras regiões..." Uma coisa é ir a Comissão do Mercosul com diversos deputados titulares, e outra, é ir apenas um parlamentar. $\mathrm{O}$ efeito é bem diferente. $\mathrm{A}$ sua atuação ficará esvaziada, se enviar apenas um parlamentar para representá-la. As comunidades vão perguntar: que prestígio tem essa comissão? Apenas um parlamentar a representa? Será muito mais eficaz fazermos dois encontros mensais da Comissão do Mercosul no interior, e dois nesta Assembléia Legislativa.

Percebe-se que a base eleitoral tende a funcionar com proximidade a um distrito no caso de muitos deputados que atuam na comissão, pelo fato de apresentarem votação concentrada, como se disse. O interesse pela região que tem por base eleitoral, às vezes, aparece expresso para futuros pleitos, como é o caso de Caio Riela, no trecho transcrito a seguir:

Entusiasmei-me tanto com essa questão que estarei renunciando meu mandato dia 31 de dezembro deste ano com o objetivo de assumir a Prefeitura de Uruguaiana e preparar aquela cidade para essa verdadeira integração que começa pela base, com esse incentivo. Muito obrigado. ${ }^{12}$

Vale analisar a atuação de um último deputado que atua de

12 Extraído de sua participação na reunião do dia 22 de maio de 1996, cuja transcrição da reunião gravada se encontra disponível on line no site da Assembleia Legislativa do Rio Grande do Sul: http://www.alrs.gov.br/anais. Acesso em 10 de setembro de 2004. 
forma bastante presente na comissão, o deputado Manoel Maria. Este possuía a sua segunda maior base eleitoral no município de Uruguaiana, apesar de ter sua votação bastante pulverizada. Atuava, contudo, em instâncias de representação parlamentar em nível nacional como a UNALE, União dos Legislativos Estaduais, sendo que a sua participação em atividades internacionais também ocorre.

Os deputados estaduais da Zona do Pampa revelaram maior interesse em servir como mediadores para as atividades da Comissão se realizadas em determinados municípios. Quanto ao agendamento de reuniões, ainda se salienta outra face que é a da divisão do estado do Rio Grande do Sul em Metade Norte e Metade Sul, no que se refere ao desenvolvimento econômico. Segundo a transcrição das reuniões, os representantes da região da Fronteira Oeste e Campanha se vinculam também a esta perspectiva. Esta posição, enquanto Metade Sul do estado é a outra expressão regional que aparece vinculada à imagem da fronteira. Os deputados comentam que os municípios que representam são ligados à Metade Sul do Estado do Rio Grande do Sul e que têm se caracterizado pelas dificuldades econômicas e de desenvolvimento. Assim, se forma na comissão mais uma instância de reivindicação.

Tal fato também se repete com a fronteira sul, em específico, e com cidades de maior potencial da Região Sul ${ }^{13}$, que adiante será

13 Toma-se como Região Sul do Rio Grande do Sul, a região que corresponde aos municípios de Pelotas, Jaguarão, Arroio do Padre, Arroio Grande, Canguçu, Capão do Leão, Amaral Ferrador, Santa Vitória do Palmar, Chuí, Turuçu, Pinheiro Machado, São José do Norte, São Lourenço do Sul, Cerrito, Rio Grande,Piratini, Santana da Boa Vista, Cristal, Herval, Pedras Altas e Pedro Osório. 
analisada. A Região Sul do estado do Rio Grande do Sul, quando enfocada nos trabalhos de interiorização da Comissão do Mercosul, aparece ligada ora a questões de desenvolvimento, enquanto Metade Sul do estado, ora a questões de fronteira.

$\mathrm{Na} 49^{a}$ Legislatura, o deputado estadual Bernardo de Souza contava com base eleitoral no município de Pelotas e imediações. A Comissão chega mesmo a dedicar uma reunião específica para tratar do desenvolvimento das potencialidades da Região Sul do estado, sendo a sua presença destacada como a de um dos principais organizadores. No caso das questões de fronteira, exemplificam-se as dificuldades de comércio e aduana levadas pelo município de Jaguarão com a cidade vizinha de Rio Branco, sendo o tema tratado por duas reuniões na cidade nos anos de 2001 e 2002. Em comum, vê-se a mesma perspectiva de encaminhamento de propostas de resolução de problemas por parte da Comissão aos órgãos competentes, como consulados e o Ministério das Relações Exteriores.

Em relação à questão do turismo, também há exemplos de atuação parlamentar, como a manifestação de Bernardo de Souza, um dos poucos parlamentares presentes na reunião, indicando o seu interesse no turismo de água doce, o que beneficiaria a sua região, correspondente ao município de Pelotas e imediações: ${ }^{14}$

14 Opta-se por transcrever a manifestação deste deputado que possui sua base eleitoral fora da região litorânea neste item, e não quando se faz referência à Região Sul do estado, em virtude de contextualizar sua participação no lançamento de um projeto que, em princípio, não beneficiaria especificamente a sua região, mas que devido ao turismo em água doce poderia trazer-Ihe vantagens. 
InterAção | 247

Temos o litoral marítimo e o litoral de água doce, o da lagoa, do mar doce. Pelotas, a nossa cidade santa, está bem situada. Há todo um conjunto de municípios. ${ }^{15}$

Já a região litorânea do estado aparece ligada ao turismo marítimo, uma vez que há grande trânsito de uruguaios e argentinos nas praias gaúchas. Seu representante, o Deputado Ciro Simoni, chega a chamar atenção para o fato de que as atenções da Comissão não se voltem para a questão das fronteiras apenas, tal como se percebe pela sua manifestação ainda na primeira reunião:

É óbvio que temos a preocupação em discutir as questões fronteiriças, mas precisamos também nos aproximar daqueles setores com potencial de desenvolvimento, como é o caso do turismo. ${ }^{16}$

A atuação do deputado será voltada na comissão para este trabalho com o turismo que beneficiaria a sua região, constituinte também da sua base eleitoral. De sua autoria, é implantado, com o auxílio da Assembleia Legislativa, o Projeto Mercotur, lançado ainda no ano de 1996. Este tinha por objetivo promover maior integração entre os órgãos governamentais, em todos os níveis, entre entidades públicas e privadas que atuam na área de turismo, promovendo a dis-

15 Extraído de sua participação na reunião do dia 30 de outubro de 1996, cuja transcrição da reunião gravada se encontra disponível on line no site da Assembleia Legislativa do Rio Grande do Sul: http://www.alrs.gov.br/anais. Acesso em 10 de setembro de 2004.

16 Extraído de sua participação na reunião do dia 15 de maio de 1996, cuja transcrição da reunião gravada se encontra disponível on line no site da Assembleia Legislativa do Rio Grande do Sul: http://www.alrs.gov.br/anais. Acesso em 10 de setembro de 2004. 
cussão e estabelecendo estratégias que possibilitassem ações recíprocas de intercâmbio turístico para o verão de 1996/1997.

Já a situação de polarização entre a oposição e o governo, dentro dos trabalhos da comissão, se faz perceptível na 50a Legislatura. A maioria dos deputados estaduais fazia oposição ao governador Olívio Dutra (PT). Da mesma forma, se salientava uma oposição dos deputados apoiadores do governo estadual com relação à política do governo federal de Fernando Henrique Cardoso. Discutem-se temas sensíveis, como a implantação da Área de Livre Comércio das Américas (ALCA), o combate à febre aftosa e o desenvolvimento regional, através do apoio à iniciativa privada, por exemplo. Esta questão fez com que houvesse uma nova maneira de se organizar os discursos, havendo a necessidade de se colocar ora na defesa ora no ataque aos governos de interesse, bem como frisar que o objetivo da Comissão era maior do que as nuances partidárias, quando envolveria o Rio Grande do Sul como um todo.

Os deputados estabelecem, contudo, uma relação com um dos polos em questão e firmam-se nesta posição, como representantes dos eleitores apoiadores ou contrários ao governo estadual ou federal. Um caso peculiar é o da indústria automotiva Ford. A implantação de sua fábrica de automóveis teve os subsídios contestados pelo governo de Olívio Dutra (PT), que aparecia com um projeto de governo que diferia economicamente do Governo Britto (PMDB). Para a discussão deste tema, a Comissão do Mercosul promoveu um debate em parceria com a Comissão de Economia e Desenvolvimento que era presidida, à época, pelo deputado Manoel Maria, membro das duas comissões. 
Neste evento, manifestações de apoio ou desaprovação às atitudes do governo pautaram as discussões, quer os deputados fossem membros da Comissão do Mercosul ou não. A reunião foi aberta pelo Presidente, Paulo Odone, que manifestou expectativa de que a Assembleia possa contribuir para superar o impasse com a Ford:

O Parlamento gaúcho é integrado por vários partidos políticos. Temos a certeza de que há, no horizonte de todos eles, a extrema preocupação de que possamos superar o atual impasse gerado em torno dos contratos da Ford e ver a montadora instalada em nosso Estado, juntamente com as suas sistemistas, suas fornecedoras e todas as resultantes do complexo automotivo. ${ }^{17}$

As discussões a respeito do turismo no estado passaram a abordar não apenas os projetos para a melhoria de infraestrutura e intercâmbio turístico, como na legislatura que acompanhou o governo de Antonio Britto. Diferentemente da 49a Legislatura, desta vez, as discussões da Comissão foram relacionadas à questão da segurança ao turista. Com isso, os deputados da oposição tentavam revelar a incapacidade do estado do Rio Grande do Sul de promover uma imagem de eficiência em segurança pública. Ocorre que, nesta época, a segurança pública era um dos pontos de polêmica entre governo e oposição, envolvendo assuntos que fugiriam do tema turismo, propriamente dito, e mesmo de temas de integração regional.

17 Extraído de sua participação reunião do dia 07 de abril de 1999, cuja transcrição da reunião gravada se encontra disponível on line no site da Assembleia Legislativa do Rio Grande do Sul: http://www.alrs.gov.br/anais. Acesso em 11 de setembro de 2004. 
Percebe-se que as questões ideológicas e partidárias são também levadas para esta discussão, ocorrendo uma tomada de posições que envolviam aspectos nacionais e internacionais como críticas ao governo federal e a assuntos internacionais.

Em outro debate, em que também se chocavam os interesses entre o governo e a oposição, aparece o surto de aftosa que atingiu o estado e que foi ligado aos debates da Comissão. Observa-se a mesma tensão entre a oposição e governo na participação de deputados e membros do governo Olívio Dutra. Para tanto, a Comissão do Mercosul chega a fazer reunião conjunta com a Comissão de Agricultura da Assembleia Legislativa presidida pelo Deputado Frederico Antunes. Vale salientar que, nestes momentos, a posição partidária aparece de forma mais clara, havendo a participação de deputados que não tinham vinculação expressiva na Comissão do Mercosul, um exemplo disto é transcrito da fala do deputado do PT, Elvino Bohn Gass:

... a posição da Bancada do PT e a do próprio Governo é de que há muito tempo atrás já deveria ter sido feita a vacinação, mas não que não houve disposição de alguns setores do Estado, nem do Governo Federal, tardando assim o procedimento e trazendo prejuízo, deixando claro o equívoco ocorrido.18

Comparada à 49a legislatura, o interesse na participação dos trabalhos da Comissão aumentou consideravelmente para os depu-

18 Extraído de sua participação reunião do dia 23 de maio de 2001, cuja transcrição da reunião gravada se encontra disponível on line no site da Assembleia Legislativa do Rio Grande do Sul: http://www.alrs.gov.br/anais. Acesso em 12 de setembro de 2004. 
tados com uma política dita de esquerda. $\mathrm{Na}$ legislatura citada, em especial no caso dos deputados Bernardo de Souza e Ciro Simoni, vê-se que apesar de estarem vinculados a partidos que dentro de um espectro partidário também seriam de esquerda, não apresentaram diferença em sua atuação em relação à dos demais deputados, atendendo a interesses paroquiais.

$\mathrm{Na} 50^{\text {a }}$ Legislatura, ocorre um diferencial nos conteúdos dos trabalhos por atuação dos deputados do maior partido de esquerda, o PT. Luis Fernando Schmidt e Maria do Rosário são os expoentes deste polo político, sendo os que mais se destacaram. Sua atuação e interesse se pautam não em questões regionais, mas em discussões a respeito de temas gerais, diluídos em assuntos internacionais e de integração regional.

Retira-se, por exemplo, um trecho da participação do deputado Luis Fernando Schmidt:

Temos [...] a tendência de - até por influência da discussão que há na grande mídia - tratarmos o Mercosul apenas na questão econômica, esquecendo-nos das questões culturais, educacionais e outras. ${ }^{19}$

Ainda é importante frisar que tanto este deputado, quanto a deputada Maria do Rosário, se dedicam à promoção de debates sobre a participação do Brasil na ALCA, o que se tornou objeto de

19 Extraído de sua participação reunião do dia 10 de março de 1999, cuja transcrição da reunião gravada se encontra disponível on line no site da Assembleia Legislativa do Rio Grande do Sul: http://www.alrs.gov.br/anais. Acesso em 11 de setembro de 2004. 
uma reunião específica da Comissão por sugestão desta deputada. Da mesma forma, a mesma Maria do Rosário Nunes ${ }^{20}$ procurou dedicar seu trabalho na comissão para o debate num tom que também fugisse à temática meramente regional ou ligada ao comércio em específico. Em sua atividade, procurou promover fóruns de debate sobre direitos humanos, como a questão da mulher no Mercosul, e para um processo de globalização diferente do seguido atualmente, como se vê na transcrição reproduzida a seguir:

Portanto, desejo fazer esta consideração e dizer que não participo daqueles segmentos que compreendem a globalização como algo que é determinado primeiro pela economia e pelo interesse do mercado. Penso que a globalização, em verdade, a ALCA, está sujeita, antes de tudo, a uma lógica política que vive a pressão da economia e do mercado, mas os Estados e os Parlamentos devem exercer um certo poder já durante a discussão do próprio processo, como a Comissão do Mercosul faz neste momento. ${ }^{21}$

A partir da análise das transcrições, procura-se demonstrar que houve uma mudança no conteúdo das reuniões analisadas de uma legislatura para outra, uma vez que se apresentou um deslocamento do interesse da comissão de temas regionais e paroquiais para assuntos de ordem geral, nacional e internacional. A causa é não apenas

20 Para fins de registro bibliográfico, a deputada em questão não costuma usar o seu sobrenome na vida pública.

21 Extraído de sua participação reunião do dia 09 de maio de 2001, cuja transcrição da reunião gravada se encontra disponível on line no site da Assembleia Legislativa do Rio Grande do Sul: http://www.alrs.gov.br/anais. Acesso em 12 de setembro de 2004. 
a polarização entre governo e oposição. Ocorre, também, o aparecimento de membros atuantes na comissão, que não se vinculavam a redutos eleitorais solicitantes de demandas, de certa forma, urgentes no que tange à integração com os países do Mercosul, como as questões fronteiriças e de turismo elencadas primeiramente.

\section{CONSIDERAÇÕES FINAIS}

Percebe-se, com a análise das reuniões da Comissão do Mercosul, que a mesma, apesar de lidar com um tema que se remeteria para âmbito internacional, prende-se, no período estudado, às questões locais ou de cunho ideológico.

Impedida institucionalmente de legislar ou negociar diretamente uma política de integração, a Comissão adota como forma de trabalho procedimentos como a interiorização. Esta aproxima o deputado estadual de sua base eleitoral, o que se torna interessante na medida em que o deputado consegue identificar o seu trabalho com a atuação perto daquilo que a sua comunidade reivindica. No bojo de uma perspectiva integracionista, se salienta através da realização de reuniões em suas bases eleitorais ou na própria Assembleia, a discussão de desenvolvimento regional, seja através do turismo no caso das cidades litorâneas, seja através de resolução de questões fronteiriças. Assim, considerando-se um modelo distributivista, se consegue explicar a atuação dos deputados que fomentam estas discussões como parte de sua estratégia para a eleição, pois trabalham com os temas paroquiais inseridos ou diluídos na questão da integração latino-americana. Ganham, com isso, visibilidade nas suas bases eleitorais, sendo 
que estas funcionariam como uma espécie de distritos eleitorais não institucionalizados. Aparecem, então, como os articuladores da resolução de demandas destas bases aos fóruns competentes.

Por outro lado, a Comissão pode se tornar palco de discussões que envolvem ideologia e, portanto, interessam aos partidos e deputados como representantes de um pensamento político. Tais discussões entram na agenda destes partidos. Ficam, assim, próximos aos eleitores que compartilham a sua cor partidária, tentando garantir a sua identificação com estes. Conseguem ser os incentivadores da construção de um pensamento sobre como deve ser feita a integração latino-americana ou como se deve agir quanto aos problemas que dela surgem. Aí estão os seus ganhos políticos.

No que se refere às funções que as legislaturas assumem com relação à temática do Mercosul, o estudo da Comissão mostra que as mesmas possuem características de representação e articulação e de agregação de interesses. $\mathrm{Na}$ medida em que os deputados identificam-se com as regiões de seus redutos eleitorais, de forma a parecer como igual, entre seus eleitores, primam pela função de representação. A possibilidade de articulação e agregação de interesses, através do trabalho dos mesmos, dá-se quando são colocados como mediadores entre a população e órgãos competentes, como dito anteriormente. De forma mais particular, a 50a Legislatura teve na Comissão um local para exercer a função de supervisão, fiscalização e observação do Poder Executivo, pela própria polarização ideológica existente no parlamento gaúcho.

Quanto à paradiplomacia, vê-se que a mesma se dá em sentido estrito, de forma disciplinada ao poder central da federação. Exis- 
te a atuação parlamentar para a mediação de problemas localizados frente aos órgãos competentes de esfera federal, ou através de projetos que visam auxiliar a integração regional em setores específicos. Não há aqui uma radicalização política, como a de reivindicar a celebração de tratados ou convênios que feririam a Constituição Federal. A ausência desta radicalização, bem como a existência disciplinar citada, podem ser dadas pela maneira como a própria Comissão se coloca: como divulgadora do processo de integração e como espaço para debates e interiorização das atividades do Parlamento gaúcho.

Conclui-se, assim, que os deputados estaduais apresentam ganhos políticos, ao garantir uma forma de se apresentar como seres capazes de espelhar o que as suas bases eleitorais pensam ou necessitam, visando, assim, à sua perpetuação como representantes ou governantes das mesmas no Poder Legislativo do Rio Grande do Sul e mesmo em outras esferas políticas.

\section{REFERÊNCIAS}

BRASIL. Constituição da República Federativa do Brasil. Brasília: Centro Gráfico, 1988.

BICCA, João Manoel. Discurso do Vereador João Manoel Bicca na Reunião de 15 de maio de 1996. Disponível em: <http://www.alrs.gov. br/anais >. Acesso em 10 set 2004.

GASS, Elvino Bohn. Discurso do Deputado Elvino Bohn Gass na Reunião de 23 de maio de 2001. Disponível em: <http://www.alrs.gov. br/anais>. Acesso em 12 set 2004. 
LA PALOMBARA, Joseph. A Política no interior das nações. Brasília: UnB, 1982

ODONE, Paulo. Discurso do Deputado Paulo Odone na Reunião de 07 de abril de 1999. Disponível em: <http://www.alrs.gov.br/anais>. Acesso em 11 set 2004

PEIXOTO, Marco. Discurso do Deputado Marco Peixoto na Reunião de 15 de maio de 1996. Disponível em: <http://www.alrs.gov.br/anais>. Acesso em 10 set 2004.

Discurso do Deputado Marco Peixoto na Reunião de 24 de março de 1996. Disponível em: <http://www.alrs.gov.br/anais>. Acesso em 12 set 2004.

Discurso do Deputado Marco Peixoto na Reunião de 07 de agosto de 1996. Disponível em: <http://www.alrs.gov.br/anais>. Acesso em 12 set 2004

LIMONGI, Fernando. O Novo Institucionalismo e os estudos legislativos: A literatura norte-americana recente. Revista Brasileira de Informação Bibliográfica em Ciências Sociais - BIB. Rio de Janeiro, n. 37, 1 semestre de 1994, pp.3-38

NUNES, Maria do Rosário. Discurso do Deputada Maria do Rosário na Reunião de 12 de setembro de 2001. Disponível em: <http://www. alrs.gov.br/anais>. Acesso em 12 set 2004.

RIELA, Caio Repiso. Discurso do Deputado Caio Repiso Riela na Reunião de 15 de maio de 1996. Disponível em: <http://www.alrs.gov. br/anais>. Acesso em 10 set 2004.

Discurso do Deputado Caio Repiso Riela na Reunião de 22 de maio de 1996. Disponível em: <http://www.alrs.gov.br/anais >. Acesso 
em 10 set 2004.

SCHMIDT, Luis Fernando. Discurso do Deputado Luis Fernando Schmidt na Reunião de 10 de março de 1999. Disponível em: <http:// www.alrs.gov.br/anais>. Acesso em 11 set 2004

SIMONI, Ciro. Discurso do Deputado Ciro Simoni na Reunião de 15 de maio de 1996. Disponível em: <http://www.alrs.gov.br/anais >. Acesso em 10 set 2004 .

SEITENFUS, Ricardo. Relações Internacionais. Barueri: Manole, 2004.

SOUZA, Bernardo de. Discurso do Bernardo de Souza na Reunião de 30 de outubro de 1996. Disponível em: <http://www.alrs.gov.br/anais>. Acesso em 10 set 2004.

Discurso do Bernardo de Souza na Reunião de 21 de agosto de 1997. Disponível em: <http://www.alrs.gov.br/anais>. Acesso em 11 set 2004.

UNIVERSIDADE FEDERAL DO RIO GRANDE DO SUL. Núcleo de Pesquisa e Ética em Gestão Social - NUPEGS. Disponível em: < www.nupegs.ufrgs.ifch.br>. Acesso em 03 set. 2005. 
258 | InterAção 